8. Гусейнова А. Г. Особенности интерактивных форм работы музеев образовательных организаций Ярославской области // Современные проблемы сервиса и туризма. 2016. № 2. С. 64-71

9. Глушкова П. В. Интерактивная экспозиция как форма презентации традиционной игры телеутов // Учёные записки (Алтайская государственная академия культуры и искусств). 2019. № 2. C. $70-73$.

УДК 793.3(571.150+571.14)(=161.1):377.1:008(571.150)

DOI: $10.32340 / 2514-772 X-2020-1-52-57$

Е. Н. Эйхольц

Алтайский краевой колледж культуры и искусств elena.eiholts@yandex.ru

\title{
ПЕРВЫЕ ШАГИ В ОСВОЕНИИ ПЛЯСКИ - ОДНОЙ ИЗ ФОРМ ФОЛЬКЛОРНОЙ ХОРЕОГРАФИИ
}

\begin{abstract}
Аннотация. Данная статья, посвящённая изучению и освоению такого жанра фольклорной хореографии как пляска, опирается на материалы полевых исследований в Алтайском крае, Новосибирской области и на многолетний опыт работы автора в Алтайском краевом колледже культуры и искусств по теме «Фольклорный танец». Статья может быть интересна руководителям фольклорных коллективов, студентам специализации «Народное художественное творчество», «Хореографическое творчество», преподавателям фольклорных отделений детских музыкальных школ и детских школ искусств, всем интересующимся русской традиционной культурой и фольклорной хореографией.

Ключевые слова: традиция, экспедиционные исследования, пляска, импровизация, координация, эмочия, копирование, мастерство, усвоение элементов, мышечное ощущение, пульсация, обучение, варианты исполнения ,традиционные наигрыши.
\end{abstract}

Каждый фольклорный танец по-своему интересен и сложен. Войти в мир танца не так просто как кажется. Любое произведение танцевального фольклора не сразу раскрывает символику жанра. Необходимо войти в ситуацию события, вдуматься в танец, вжиться в него, чувствуя, накапливая и передавая возникшую энергетику. Пришедшая к нам из глубины веков, пляска, так же как и хоровод, и народно бытовые танцы малой формы, относятся к основным жанром русского танца. Пляска открывает большой простор, как для индивидуального, так и массового творчества.

Секрет пляски состоит в том, что участник определённых ситуаций в календарно-обрядовых или семейно-обрядовых событиях не может всегда быть только зрителем. Наступает момент, когда происходит эмоциональный всплеск. Появляется потребность выплеснуть накопившуюся энергию в индивидуальном импровизационном танце и зритель становится участником-исполнителем. «Импровизация - характерная особенность русской пляски» [1, с. 13].

Пляска со своей виртуозной импровизацией красивейшая народная традиция. Она просто и естественно переходит от поколения к поколению - дети перенимают её у отцов, как те перенимали у дедов. Несмотря на то, что преемственность поко- лений в танце существовала всегда, плясуноввиртуозов в Алтайском крае встречалось мало. В селе Верх-Уймон Усть-Коксинского района жил мастер импровизационной пляски, о котором вспоминала Захарова Матрёна Лукинична, 1920 г. p. [2]. Однажды в споре он переплясал цыгана, тем самым освободил своё село от систематического нашествия цыганского табора. В. А. Липинская публикует информацию, полученную от сибирячки А.Е. Петровой, которая не одобряла новомодные манеры в танцах: «Сейчас танцуют готовы пол проломить. А мы танцевали - свечку на голову поставишь, не упадёт»[3, с. 173]. Переселенцы привезли в Сибирь «Товарочку» - пение частушек женской парой под гармонь и перепляс «дроби». «Пение сопровождалось плясками и дробным пристукиванием каблуками» »[3, с. 173].

Во время исполнения своего танца участники как бы «приглядываются», «присматриваются» к себе, ловят собственный отклик на танец. Исполнительское мастерство приобреталось постепенно, формируясь с самого детства. Из воспоминаний Сосниной Матрёна Григорьевна, 1931 г. р., уроженки села Песчаная Солонешенского района, на тот момент жительницы села Красный партизан Чарышского района: «При свободной минутке в школе, на переменке, обопрусь руками о столы, 
рядом стоящие, одной об один, другой о другой, как бы повисая в воздухе, и ну ногами перебирать, так и училась...» [4]. Хотя считается, что сама пляска не готовится заранее. Всё происходит как бы впервые. Процесс танца (создание - исполнение - восприятие) протекает естественно и непринуждённо. Мастер-исполнитель импровизирует на основе традиционных локальных движений и ритмов традиционных наигрышей, выплёскивая в своём танце сиюминутное душевное эмоциональное состояние.

Естественно встаёт вопрос: как научиться мастерству импровизации в пляске?

При обучении импровизации все формы практических занятий должны способствовать проявлению собственной инициативы обучающихся, их стремлению повторить (скопировать) этнографический материал и на основе этого создать что-то своё, новое, лучшее, естественно, не выходя за рамки осваиваемой традиции. В обучении импровизации большое внимание уделяется не самостоятельности отдельного танца, а внутренней связи движений с эмоциональными впечатлениями и музыкально-ритмической организацией. Исполнитель проживает в танце определённое событие, выражая своё состояние на данное время.

Формированию навыка импровизации способствуют:

- просмотр видеозаписей плясок мастеров народной хореографии с акцентированием внимания на определённой локальной традиции;

- развитие умения наиболее точно копировать танцевальные движения;

- умение вычленить мельчайшие нюансы при просмотре видеозаписей плясок мастеров народной хореографии;

- развитие способности сиюминутно выявить в движениях эмоциональное, импульсивное, спонтанное прочтение незнакомого музыкального наигрыша, умение слышать с опережением;

- внимательное освоение метроритмического построения в композиции танца, составленного самостоятельно, с помощью мастера- информатора или преподавателя.

Обучение импровизационной пляске - процесс достаточно сложный и длительный. Чтобы научить обучающегося языком движения тела выражать свои чувства, эмоции, которые возникают обычно спонтанно в различных ситуациях, сформировать у него умение найти, создать свой индивидуальный образ, обязательно нужно:

- создать атмосферу творческой заинтересованности, опираясь на знания характерных особенностей изучаемой локальной традиции, не только танцевальной, но и календарной, и семейно-обрядовой;

- мотивировать процесс обучения (ответив на вопрос «зачем?»);

- пробудить в ученике веру в себя;

- научиться уважать каждое самостоятельно найденное решение, даже если оно не всегда интересно.

Только тогда процесс обучения будет не только понятным, но и эмоционально увлекательным.

Импровизация - это сочинение в процессе исполнения на основе ранее выученных движений. Поэтому исполнитель обязан владеть определённым запасом танцевальной лексики и танцевальной техникой, а для этого необходимо развивать следующие навыки:

- слышать музыку с опережением в начале музыкальных фраз, т.е. уметь слышать внутренний ритм музыки;

- владеть мышечным ощущением каждого движения;

- уметь организовать движения индивидуального танца в пространстве;

- уметь копировать движения мастеров пляски, характерные для определённой локальной традиции;

- знать основные исполнительские особенности, которые встречаются во всех региональных хореографических традициях.

К основным исполнительским особенностям относятся:

- синкретичность (синтетичность) музыкально-хореографических текстов - исполнение танцев под песни (хоровод), песен под танцы (кадриль);

- кантилена хода, которая достигается за счёт «рессорности» шагов, т. е. во время исполнения простых шагов в хороводе, дробей в пляске, различных танцевальных «проходок» колени танцоров не выпрямляются до конца, а остаются немного присогнутыми. Одна из причин наличия кантилены движения в хореографической традиции - необходимость сохранять устойчивое положение корпуса, чтобы дыхание не сбивалось и не мешало пению;

- полицентрика - принципиально разные по характеру движения рук и ног. Полицентрика особенно хорошо видна у мастеров-плясунов, когда их ноги выполняют жёсткую, чёткую партию (дроби), а руки при этом двигаются более свободно и плавно. Сочетание однохарактерных, синхронных и симметричных движений рук и ног иногда служит для создания комического эффекта в пляске;

- полиритмика - одновременное исполнение двумя или более танцорами движений с различными ритмическими рисунками («пересек»). В 
пляске каждый из исполнителей ритмически импровизирует, учитывая ритм звучащей песни или инструментального наигрыша как проявление общей ритмической основы;

- импровизационность исполнения - отсутствие заранее продуманного плана действий, рождение танца на ходу, без предварительной подготовки.

Все вышеперечисленные особенности народной хореографии позволяют исполнителям осуществить принцип импровизационности, который из чисто технического приёма переходит в категорию эстетическую.

Внешняя выразительность элементов танца, тончайшие нюансы не являются самостоятельными порождениями действий человека. Такая выразительность во многом формируется внутренним ритмом звучащей музыки, отражая в движениях, как ярких, так и еле уловимых, наиболее сильные акценты ритма. Ритм этот основан на внутренней пульсации, существующем в каждом человеке. Пульсация - это внутренняя вибрация, отклик организма на песню, мелодию наигрыша. Это деление звуков мелодии на доли - целые, половинки, четверти, восьмушки, шестнадцатые и паузы.

Значение пульсации для исполнителя особенно важно: музыкальные наигрыши к пляске вызывают такую силу эмоций, которая, воздействуя на исполнителя, наилучшим образом способна привести к результату - созданию всегда разного хореографического произведения.

Без ощущения внутренней пульсации, непрерывной ритмической цепи, невозможно импровизировать, а значит, создавать индивидуальный танец. Только чувствуя общее состояние ритма, можно произвести уже собственные элементы танца.

Влияя на активность движений пляшущего, внутренняя пульсация сама практически рождает движения. Гармония, возникающая от внутреннего ощущения ритма и внешнего его источника (наигрыша), упорядочивает слушание и приводит танцора в состояние эмоционального переживания.

При обучении импровизационному танцу выявляется ряд проблем:

- исполнитель, ощущая пульсацию, не может перевести самостоятельно одно движение в другое;

- или, наоборот, не может уже освоенные движения согласовать с музыкой, т. е. с различными её темпами.

Возникает вопрос: «Что делать?». Опираясь на многолетний опыт своей работы в области народного танца, автор рекомендует в некоторых случаях работать над освоением танцевальных движений без музыкального сопровождения. При этом интуитивно нужно вычленять начало образования движения танца, варьировать длительностями: например, счёт по тактам можно укрупнить или, наоборот, уменьшить.

Освоив ряд движений, соединив их в комбинации, нужно пробовать исполнять их под музыку. И в данной ситуации могут возникнуть проблемы: некоторые движения просто не подойдут, «не лягут» на определённый музыкальный наигрыш. И вот теперь наступает момент импровизации. Исполнитель, чувствуя несоответствие внутреннего и внешнего ощущений, меняет или видоизменяет ряд движений, дополняя их соответствующим характером и определённой индивидуальной манерой.

Неоднократно повторяя освоенные движения, исполнителю непроизвольно захочется каждый раз при смене музыкального сопровождения добавлять в свой танец всё новые и новые движения. Появляется азарт в исполнении танца и невольный интерес: «А что же будет дальше?». А дальше «коленца» в пляске благодаря внутренней мышечной и зрительной памяти будут складываться из ранее увиденных или освоенных проходок, кадрильных шагов, дробных выстукиваний. Сольная пляска будет складываться, раскрываться из сиюминутного чувствования общего и личного настроения; перепляс будет захватывать своей соревновательностью, парная пляска - выражением отношения к партнёру, групповая пляска будет передавать общую историю национального единения. У каждой национальности есть определённые движения, зависящие в том числе и от географического расположения, и от климатических условий, которые сразу характеризуют танец. В каждом движения танца символически зашифрованы определённые настроения на события из истории общества, государства в целом. Групповая пляска передаёт не только общее настроение, которое естественным образом передаётся от исполнителя к исполнителю, а общий национальный дух. Импровизационная пляска - это проявление высшего мастерства в танцевальной культуре, к нему стремились с детства, но не все постигали это мастерство. А плясали и пели то все, используя индивидуальные навыки в групповой и массовой пляске.

Необходимо ещё раз отметить: чтобы процесс умения в определённой ситуации сиюминутно импровизировать приносил только положительные эмоции, нужно уделять особое внимание мышечному ощущению движений тела, которое вырабатывается осознанно систематическими упражнениями. Научиться управлять мышцами нужно в первую очередь для того, чтобы постепенно выработался навык саморегуляции, владения собственным эмоциональным состоянием. При целена- 
правленном и активном усвоении определённых упражнений происходит образование «мышечного корсета». Пластические возможности человека безграничны. Самостоятельное управление напряжением мышц тела снимает напряжение со всего опорно-двигательного аппарата исполнителя.

Следует напомнить, что формирование навыка управления мышечным напряжением корпуса помогает регулировать эмоциональное состояние человека и вне танца. Происходит скрытый процесс преобразования впечатлений, упорядочивания его нервного состояния. Поэтому импровизатору танца обычно не знаком психологический зажим, влияющий на подвижность тела и выразительность его эмоциональных переживаний.

Погружаясь в традицию, обучающийся регулярно занимается освоением дробных выстукиваний, копированием тех или иных «колен». Когда с помощью определённых упражнений, систематизированных во временном отрезке от «простого к сложному», а иногда наоборот, мышцы достаточно окрепнут, приобретут эластичность и пластичность, тогда и перераспределение мышечных нагрузок будет более управляемым, соответственно и координация движений более подвижной.

Умение перераспределять мышечные нагрузки поможет не только в исполнении танца, но и повлияет на внешнее впечатление, производимое исполнителем. Его осанка будет правильной, движения тела - красивыми. Ему самому уже не будут казаться сложными элементы движений и манера исполнения при копировании определённой осваиваемой традиции. Пляска - это не столько мастерство виртуозного исполнения комбинаций дробных выстукиваний, присядок, хлопушек, сколько умение чувствовать творческую ситуацию, согласовывая хореографический, песенный, музыкальный, эмоциональный текст, координируя его в пространстве.

Координация движений в пространстве определяется шагами: вперёд, назад, влево, в центр круга, из круга. Шаги эти в основном спокойные, короткие, почти шаркающие. Мелкие дробные выстукивания (дробь горохом, простая одинарная, двойная, «хромого», «в три ноги») - характерны для северорусской традиции. Прыгающие импульсивные шаги и дроби («пересеки»), «петушиные» проходки - для южнорусской традиции.

Для выработки умения координировать движения необходимо прививать обучающимся навык ориентации в круге, организовывая направления перемещения по часовой (по солнцу) или против часовой стрелки, в центр круга, из центра.

Повороты корпуса также ориентируются в круговых направлениях (четвертном развороте, половинном, целом повороте, что соответствует 90, 180, 360 градусов).

Цель упражнений по развитию координации движений в пространстве состоит в том, чтобы освоить как можно больше вариантов сочетания одноименных и разноименных движений.

Как правило, сочетание вращательных движений требует большего сосредоточения внимания, чем сочетание движений в направлениях «маятника». Однако, несмотря на простоту, движения в направлениях «маятника» в различных сочетаниях разнятся по степени усвоения. Большой успех при разучивании сложного движения достигается в том случае, когда от него не отказываются, несмотря на неудачи. Нужно стараться преодолеть трудности. Замена сложной комбинации на более простую (лёгкую), конечно, допустима, но эффект тренировки мышечных ощущений сводится к нулю.

Самостоятельный поиск - это тот путь, который поможет обучающимся прийти к пониманию импровизации в танце. Для того, чтобы он был успешен, обязательна исследовательская работа в экспедициях, а также выполнение следующих заданий:

- неоднократный внимательный просмотр видеозаписи этнографических образцов;

- повторение, «копирование» движений мастеров-исполнителей;

- движения, освоенные на занятиях, закончить своим вариантом;

- движения, освоенные на занятиях, исполнить в разной последовательности;

- выстроить освоенные движения в композицию («колено»);

- набрать как можно большее количество движений в определённый отрезок времени;

- найти варианты развития понравившихся движений;

- приобрести навык развития движений в динамике;

- на основе выученных движений сочинить варианты их комбинации («колен»).

Для развития координации перемещение в пространстве лучше всего организовать по кругу, что соответствует традиционному исполнению произведений танцевальной культуры русского населения Алтайского края.

Танцевальные движения могут быть построены на бытовом шаге или «кадрильном» шаге, шаркающем шаге, простых дробных выстукиваниях. Также их можно использовать:

- с четвертными разворотами (90 градусов);

- половинными поворотами (180 градусов);

- полным поворотом вокруг себя (360 градусов); 
- со сменой мест в различных направлениях в парах - лицом друг к другу, спиной друг к другу, «до-за-до».

Танцевальные движения в пространстве обязательно сочетаются с движениями рук. Нужно знать, что движение и положение рук должно быть свободным и может зависеть от ощущения комфорта и удовольствия исполнителя, от чувствования произведения, от ощущения оторванности их от корпуса; от фантазии танцора. Положение рук зависит и от региональной традиции исполнения (северорусской, южнорусской):

- свободное движение рук перед собой или сбоку не выше уровня груди - северорусская традиция;

- свободное движение рук, разнообразные нюансы, положения и движения кистей выше уровня груди или даже головы - южнорусская традиция.

пляске-импровизации важную роль играет музыкальный материал. Естественно, что это должны быть живые звуки гармони или балалайки. Наигрыши должны соответствовать тем или иным стилевым особенностям определённых районов, танцевальная традиция которых осваивается. При разучивании базовых движений необходимо, чтобы звучала одинаковая мелодия для более чёткого метроритмического деления, слышанья всех нюансов, которые будут влиять на характер исполнения танца. Только тогда, когда исполнители научатся слушать, слышать музыку, ориентироваться в ней, чувствовать её внутреннюю пульсацию, можно менять наигрыш как можно чаще для активизации их ощущений себя в танце. Самым сложным, но достаточно притягательным своей необычностью является аккомпанемент «под язык» (имитация музыкального наигрыша собственным голосом). «Под язык» исполнители пляшут, когда нет инструментального сопровождения, чем ещё больше удивляют и покоряют любителей традиционной пляски. Тексты такого голосового сопровождения состоят из многократного повторяющегося сочетания слов «тува, тува, тува, тува» или « тына, да, да, тына, тына, тына» или любых других. Напев может исполняться одноголосно или в подвижном многоголосии, уходящем в унисон. Песенное сопровождение, например «частушки», могут накладываться на голосовую имитацию гармони или звучать как «проигрыш» [5]. Пляска «под язык» - это один из приёмов групповой пляски, бытовавших в районах Алтайского края, и это очередной шаг к исполнительскому мастерству, мастерству импровизации. Отдельных исследований нет. Вся информация основана на результатах экспедиционных исследований Е. Эйхольц.
Бытовые фольклорные танцы зрелищны, но не рассчитаны на оценку «со стороны». Они рассчитаны на вовлечение в процесс исполнения всех присутствующих, так как это творчество как индивидуальное, так и коллективное.

Перепляс «Казачок» (Алтайский край). Записан в селе «Красный партизан» Чарышского района Алтайского края летом 1998 года Сигаревой М. Н., Головиным А. В., Эйхольц Е. Н. от Харитиньи Аристарховны Сосниной 1929 г. р., уроженки с. Красный Партизан Чарышского района.

По композиционному построению «Казачок» является переплясом. Исполняли обычно двое мужчин под балалайку, наигрыш «Яблочко», со слов информатора, следующим образом: один исполнитель вызывает поклоном своего соперника и отходит.

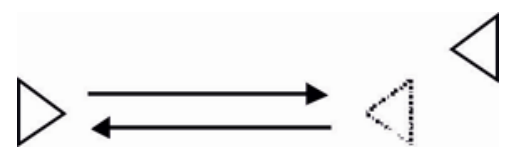

Тот, кого вызвали, пляшет, затем сам вызывает поклоном того, кто вызвал на соревнование его. Таким образом, исполнители пляшут по очереди. Побеждает тот, кто исполнит большее количество движений или более замысловатые и интересные движения, чем у соперника.

\section{Сольная женская пляска (Алтайский край)}

Пляска записана в селе Красный Партизан Чарышского района Алтайского края летом 1998 года Сигаревой М. Н., Эйхольц Е. Н., Головиным А. В. от Матрёны Григорьевны Сосниной, 1931 года рождения, уроженки села Песчаного Солонешенского района.

Музыкальное сопровождение - гармонь. Наигрыши, со слов информатора, могут быть различные - «Саратова», «Подгорная», «Товарочка».

Прежде чем войти в круг, исполнительница «проходкой» идёт по кругу. Проходка несложная кадрильный шаг, перетопы. Но затем включаются дробные выстукивания, которые по мере развития пляски, усложняются, и появляется новый элемент - ход «в три ноги» («трилистник»).

Пройдя по кругу, исполнительница выходит на середину. В центре круга исполняет всевозможные дробные комбинации («колена»):

- перекаты с носка правой ноги с перетопом и «Ключом»;

- соскоки на две ноги и перетопы на 1/8;

- одинарные дроби.

Затем снова идет проходкой по кругу шаркающим шагом, комбинируя его с «кадрильным» (переменным) шагом. При этом корпус покачивается то вправо, то влево под музыку. Руки опущены вниз, ноги почти не отрываются от пола, но 
каждый удар каблуком слышен в своём ритмическом рисунке. Невозможно описать до такта все движения пляски, так как они не имеют строгой последовательности, неповторимы по своим метроритмическим движениям, а сама пляска основана на полной импровизации, которая зависит от мастерства исполнителя.

В настоящей статье сделана попытка передачи многолетнего опыта автора как педагогаисследователя по освоению танцевального фольклора Алтайского края. Рассмотрели особенности освоения одного из танцевальных жанров - импровизационной пляски. Выявили, что подход к изучению и освоению танцевальных жанров русской традиционной культуры должно быть планомерным, методически выверенным, опираться на обязательную исследовательскую работу, включающую фольклорно - этнографические экспедиции. Представлена расшифровка этнографических образцов танцевальной культуры из экспедиционных исследований автора по Алтайскому краю.

\section{Список информаторов}

- Ананина Анастасия Михайловна, 1928 г. р.; уроженка р. п. Усть-Пристань (УстьЧарышская Пристань); жительница с. Власиха, г. Барнаул, Алтайского края (Россия);

- Васильева Анна Степановна, 1915 г. р.; уроженка Ярославской области; жительница с. Красный Партизан Чарышского района Алтайского края (Россия);

- Захарова Матрёна Лукинична, 1920 г. р.; жительница с. Верх-Уймон Усть-Коксинского района Республики Алтай (Россия);
- Пастухова Мария Васильевна, 1933 г. р.; уроженка с. Чаговка Комыслинского района Оренбургской области; жительница с. Берёзовка Чарышского района Алтайского края (Россия);

- Плотникова Любовь, 1924 г. р.; жительница с. Чарышское Чарышского района Алтайского края (Россия);

- Соснина Матрёна Григорьевна, 1931 г. р.; уроженка с. Песчаное Солонешенского района Алтайского края (Россия);

- Соснина Харитинья Аристарховна, 1929 г. р.; уроженка с. Красный Партизан Чарышского района Алтайского края (Россия).

\section{Список литературы}

1. Климов A. A. Русский народный танец. Вып. 1. Москва, 1996. 39 с.

2. Эйхольи E. Н. Личный архив. Полевые дневники фольклорно-этнографических экспедиций в села Усть-Коксинского района Республики Алтай (Россия), 1998-2000.

3. Липинская B. A. Старожилы и переселенцы. Русские на Алтае. XVIII - начало XX века. - Москва, 1996. 267 с.

4.Эйхольц Е.Н. Личный архив. Полевые дневники фольклорно-этнографических экспедиций в с. Красный партизан Чарышского района Алтайского края (Россия), 1998.

5. Эйхольц Е.Н. Личный архив. Полевые дневники фольклорно-этнографических экспедиций в с. Власиха, г. Барнаул Алтайского края (Россия), 2016. 